OPEN ACCESS

Edited by:

Roza Adany,

University of Debrecen, Hungary

Reviewed by:

Aleksandra Kovačević,

Military Medical Academy, Serbia

Mariela Deliverska,

Medical University, Sofia, Bulgaria

${ }^{*}$ Correspondence:

Dejan Baskic

dejan.baskic@gmail.com

Specialty section:

This article was submitted

to Health Economics,

a section of the journal

Frontiers in Public Health

Received: 15 June 2017

Accepted: 24 July 2017

Published: 28 August 2017

Citation:

Mišić M, Čukić J, Vidanović D, Šekler M, Matić S, VukašinovićM and

Baskić D (2017) Prevalence of

Genotypes That Determine

Resistance of Staphylococci to

Macrolides

and Lincosamides in Serbia.

Front. Public Health 5:200.

doi: 10.3389/fpubh.2017.00200

\section{Prevalence of Genotypes That Determine Resistance of Staphylococci to Macrolides and Lincosamides in Serbia}

\author{
Milena Mišić', Jelena Čukićn, Dejan Vidanovic's, Milanko Šekler ${ }^{3}$, Sanja Matic', \\ Mihailo Vukašinovic' ${ }^{4}$ and Dejan Baskic', ${ }^{2, *}$
}

\begin{abstract}
${ }^{1}$ Department of Microbiology, Public Health Institute Vranje, Vranje, Serbia, ${ }^{2}$ Department of Clinical Microbiology, Laboratory for Virology, Serology, Immunology and Molecular Diagnostics, Public Health Institute Kragujevac, Kragujevac, Serbia, ${ }^{3}$ Department of Laboratory Diagnostics, National Reference Laboratory for Avian Influenza and Newcastle Disease of Poultry Republic of Serbia, Veterinary Specialized Institute Kraljevo, Kraljevo, Serbia, ${ }^{4}$ Faculty of Medical Sciences, Doctoral Studies, University of Kragujevac, Kragujevac, Serbia, ${ }^{5}$ Center for Molecular Medicine and Stem Cell Research, Faculty of Medical Sciences, University of Kragujevac, Kragujevac, Serbia
\end{abstract}

Macrolides, lincosamides, and streptogramins (MLS) resistance genes are responsible for resistance to these antibiotics in Staphylococcus infections. The purpose of the study was to analyze the distribution of the MLS resistance genes in community- and hospitalacquired Staphylococcus isolates. The MLS resistance phenotypes [constitutive resistance to macrolide-lincosamide-streptogramin $B(c M L S b)$, inducible resistance to macrolide-lincosamide-streptogramin B (iMLSb), resistance to macrolide/macrolidestreptogramin B (M/MSb), and resistance to lincosamide-streptogramin A/streptogramin $\mathrm{B}(\mathrm{LS} / \mathrm{b} / \mathrm{b})]$ were determined by double-disc diffusion method. The presence of the MLS resistance genes (ermA, ermB, erm C, msrA/B, InuA, InuB, and IsaA) were determined by end-point polymerase chain reaction in 179 isolates of staphylococci collected during 1-year period at the Center for Microbiology of Public Health Institute in Vranje. The most frequent MLS phenotype among staphylococcal isolates, both community-acquired and hospital-acquired, was iMLSb (33.4\%). The second most frequent was M/MSb (17.6\%) with statistically significantly higher number of hospital-acquired staphylococcal isolates $(p<0.05)$. MLS resistance was mostly determined by the presence of msrA/B (35.0\%) and erm $\mathrm{C}(20.8 \%)$ genes. Examined phenotypes were mostly determined by the presence of one gene, especially by msrA/B (26.3\%) and ermC (14.5\%), but $15.6 \%$ was determined by a combination of two or more genes. M/MSb phenotype was the most frequently encoded by msrA/B (95.6\%) gene, LSa/b phenotype by InuA (56.3\%) gene, and iMLSb phenotype by ermC (29.4\%) and ermA (25.5\%) genes. Although cMLSb phenotype was mostly determined by the presence of ermC (28.9\%), combinations of two or more genes have been present too. This pattern was particularly recorded in methicillin-resistant Staphylococcus aureus (MRSA) (58.3\%) and methicillin-resistant coagulase-negative staphylococci (MRCNS) (90.9\%) isolates with cMLSB phenotype. The msrA/B gene and M/MSb phenotype were statistically significantly higher in hospital-acquired than community-acquired staphylococci strains $(p<0.05)$. There are 
no statistically significant differences between staphylococci harboring the rest of MLS resistance genes acquired in community and hospital settings $(p>0.05)$. The prevalence of iMLSb phenotypes may change over time, so it is necessary to perform periodic survey of MLS resistance phenotypes, particularly where the D-test is not performed routinely.

Keywords: staphylococci, MLS resistance, resistance phenotypes, erm genes, polymerase chain reaction genotyping, hospital-acquired infection, community-acquired infection

\section{INTRODUCTION}

The Staphylococcus spp. includes at least 40 species, some of them may cause a wide variety of diseases in humans and animals, while some of them are generally non-pathogenic and considered to be commensal. Staphylococcus aureus is one of the most important bacteria that cause skin and soft tissue infections and number of serious other medical problems in human. Today, coagulasenegative staphylococci (CNS), as opportunists, become one of a major cause of hospital acquired infection (1).

Since Staphylococcus spp. has become resistant to many important antibiotics, the possibility that "older" compounds such as erythromycin and clindamycin still have ability to maintain the efficiency is very important to keep new resistance from developing. Over the past decade, an excessive and inappropriate use of antibiotics for human and animal treatment, as well as, animal feed supplements for growth promotion, has led to an increase in a number of staphylococci acquiring cross-resistance to macrolides, lincosamides, and streptogramins (MLS) antibiotics.

The mechanisms of resistance to MLS antibiotics are mainly related to the inhibition of protein synthesis. This can be mediated by several mechanisms: (a) ribosomal binding site modification (by methylation or mutation in the 23S rRNA gene) encoded by erm genes (erm $\mathrm{A}$, erm $\mathrm{B}$, erm $\mathrm{C}$, erm $\mathrm{Y}$, and erm $\mathrm{F})$, (b) active efflux mediated by $m s r A / B$ gene, and (c) enzymatic modification of antibiotics (2).

The dimethylation of adenine A2058, at the N6 position which is located in the region of the peptidyl transferase loop in domain $\mathrm{V}$ of $23 \mathrm{~S}$ rRNA in the $50 \mathrm{~S}$ ribosomal subunit of bacteria, leads to cross-resistance between macrolides, lincosamides, and streptogramin group B (MLSb) (2). The family of genes responsible for this methylation is named erm (erythromycin ribosomal methylase) and now there are 21 different classes of identified erm genes (3). Since the erythromycin binding site on the $50 \mathrm{~S}$ ribosome subunit overlaps the binding site of the newer MLSb, the modification by methylase(s) reduces the binding of all three classes of antibiotics, causing MLSb resistance phenotype (4).

\footnotetext{
Abbreviations: MLS, macrolides, lincosamides, and streptogramins; Er/Cli S, susceptibility to erythromycin and clindamycin; cMLSb, constitutive resistance to macrolide-lincosamide-streptogramin $\mathrm{B} ; \mathrm{M} / \mathrm{MSb}$, resistance to macrolide/ macrolide-streptogramin $\mathrm{B}$; iMLSb, inducible resistance to macrolide-lincosamide-streptogramin $\mathrm{B}$; LSa/b, resistance to lincosamide-streptogramin A/streptogramin B; MSSA, methicillin-sensitive S. aureus; MRSA, methicillin-resistant $S$. aureus; MSCNS, methicillin-sensitive coagulase-negative staphyloccoci; MRCNS, methicillin-resistant coagulase-negative staphylococci; PCR, polymerase chain reaction; CLSI, Clinical and Laboratory Standards Institute.
}

The expression of erm genes is manifested as either constitutive or inducible macrolides, lincosamides, and streptogramin B phenotype [constitutive resistance to macrolide-lincosamidestreptogramin B (cMLSb) or inducible resistance to macrolidelincosamide-streptogramin B (iMLSb)]. In iMLSb phenotype, the bacteria produce inactive methylase mRNA, which becomes active only in the presence of a macrolide as an inducer. In the presence of inducer (erythromycin) a rearrangement of the mRNA occurs, allowing the methylase-coding sequence translation (5). In contrast, in bacteria showing cMLSb resistance phenotype, active methylase mRNA is produced in the absence of an inducer.

The active efflux of antibiotics is the second important mechanism of resistance in staphylococci. The $m s r \mathrm{~A}, m s r \mathrm{~B}$, and newly discovered $m s r C$ gene encode the ATP-dependent efflux pump (ABC), which determines resistance to 14-membered and 15-membered macrolides and streptogramin type B in Staphylococcus spp. (MSb resistance phenotype) (6). An active efflux ABC transporter-like transmembrane protein is encoded by $l s a$ genes: $l s a \mathrm{~A}$ and $l s a \mathrm{C}$. It belongs to mechanism of resistance mediated by active efflux of antibiotics, causing the resistance to lincosamides and streptogramin type A phenotype (7).

In contrast to MLSb resistance phenotype, specific resistance to lincosamides and streptogramin type B (LSb) is mediated by enzymatic inactivation of the antibiotic. The most important enzymes that modify antibiotics are lincosamide nucleotidyl transferases encoded by $\ln u$ genes (formerly $\operatorname{lin}$ ): $\ln u \mathrm{~A}$ and $\ln u \mathrm{~B}$ genes. In staphylococci, these enzymes are responsible for resistance to lincosamides and streptogramin type B phenotype (8).

Macrolides, lincosamides, and streptogramins resistance genes are responsible for resistance to MLS in community- and hospital-acquired Staphylococcus infections. Therefore, the purpose of the study was to analyze the distribution of the MLS resistance genes in Staphylococcus isolates and their distribution among community- and hospital-acquired isolates.

\section{MATERIALS AND METHODS}

\section{Bacterial Strains}

A total of 1,643 staphylococcus isolates collected during 1-year period at the Center for Microbiology of Public Health Institute in Vranje were obtained from various clinical specimens including nasal and throat swabs, purulent discharge, and genital secretions, originating from both outpatient and inpatient populations. Multiple specimens from the same patient were avoided. The presence of the MLS resistance genes: erm A, erm B, erm C, msrA/B, $\ln u \mathrm{~A}, \ln u \mathrm{~B}$, and $l s a \mathrm{~A}$ was determined in 179 staphylococcal isolates 
by end-point polymerase chain reaction (PCR). The bacterial DNA extraction and amplification of the specific resistance genes were performed at the Center for Microbiology Institute of Public Health in Kragujevac, Serbia.

The local ethics committee approved the study according to the Declaration of Helsinki (No. 01-5072/2013). The authors declare that informed consent was not required.

\section{Isolation and Identification}

Isolation and identification of bacterial strains were performed using routine microbiological tests. The strains were identified to the species or genus level by the conventional microbiological methods.

\section{Determination of Resistance Phenotypes}

All recovered isolates were tested by the double-disc diffusion method. The MLS resistance phenotypes: cMLSb, iMLSb, resistance to macrolide/macrolide-streptogramin B (M/MSb), and resistance to lincosamide-streptogramin A/streptogramin $\mathrm{B}(\mathrm{LSa} / \mathrm{b})$ were determined by double-disc diffusion method according to Clinical and Laboratory Standards Institute recommendations (9). Erythromycin $(15 \mu \mathrm{g})$ and clindamycin $(2 \mu \mathrm{g})$ disks were placed at an edge-to-edge distance of $12 \mathrm{~mm}$ on inoculated Mueller-Hinton agar. Resistance to erythromycin and clindamycin indicates a constitutive MLSb resistance (cMLSb). The clindamycin diffusion zone which was blunted proximal to the erythromycin disk or showing D shape was considered as inducible type of resistance (iMLSb phenotype). Susceptibility to clindamycin and resistance to erythromycin defined the M/MSb phenotype. The isolates resistant to clindamycin and sensitive to erythromycin were defined as LSa/b phenotype.

\section{Isolation of Bacterial DNA}

Bacterial DNA were extracted by PrepMan Ultra sample Preparation Reagent (Applied Biosystems, Inc.), according to the manufacturer's guidelines. All extracted DNA samples were stored at $-70^{\circ} \mathrm{C}$ prior to further analysis.

\section{Identification of Genes by Multiplex PCR}

The sequences of the primers are presented in Table 1. PCR conditions for the primer sets have been as previously described by Rizzotti et al., Matsuoka et al., Lozano et al., and Singh and Murray in their studies (10-13). The final volume of each PCR reaction was $50 \mu \mathrm{l}$ and contained $2 \mu \mathrm{l}$ of genomic DNA, $1 \mu \mathrm{l}$ of each primer (Invitrogen), $25 \mu$ l of Maxima ${ }^{\circledR}$ Hot Start Green PCR Master Mix (Fermentas), and $21 \mu \mathrm{l}$ of DEPC $\mathrm{H}_{2} \mathrm{O}$. Positive and negative controls were included in each assay. The reactions were performed using the Sa Cycler-96 thermocycler (Sacace Biotechnologies S.r.l. Como, Italy), whereas the PCR products were detected by gel electrophoresis on the E-Gel iBase (Invitrogen) in 2\% (w/v) agarose gel (E-Gel ${ }^{\circledR} 2 \%$, Invitrogen) and visualized on the Gel Doc XR System, including an ultraviolet light transilluminator (Bio-Rad) (14).

\section{Statistics}

Fisher's exact test is used to compare two proportions at a significance level of $p<0.05$. The results of the experiments are presented in tables and figures.

\section{RESULTS}

Among 1,643 examined isolates of staphylococci, 944 were identified as $S$. aureus. The rest of 699 isolates were characterized as CNS. Those isolates were further characterized by double-disc diffusion method to determine the MLS resistance phenotype. However, the largest number of staphylococcal isolates showed sensitivity to both macrolide and lincosamide (39.1\%). Among staphylococcal isolates the most common resistance phenotype was iMLSb (33.4\%), the second most prevalent was M/MSb (17.6\%). cMLSb phenotype was detected in only $8.9 \%$ of staphylococcal isolates, and the rarest detected resistance phenotype was LSa/b (1\%).

Distribution of MLS resistance phenotypes by origin of the staphylococcal isolate (community acquired versus nosocomial) is presented in Table 2 . The most frequent MLS phenotype among staphylococci isolates, both community-acquired and hospital-acquired, was iMLSb. There were no statistically significant differences between community- and hospital-acquired staphylococci isolates showing iMLSb, cMLSb, LSa/b phenotype, and sensitivity to both erythromycin and clindamycin $(p>0.05)$. However, there was statistically significantly higher number of hospital-acquired staphylococcal isolates showing M/MSb phenotype $(p<0.05)$ (Table 2$)$.

One hundred and 79 strains of staphylococcus isolates showing different MLS phenotypes were selected for further analysis. End-point PCR was performed to detect clinically relevant MLS resistance genes. The most commonly detected MLS resistance genes among staphylococci isolates were $m s r \mathrm{~A} / \mathrm{B}$, followed by erm genes: erm $\mathrm{C}$, erm $\mathrm{B}$, and ermA. In $9.8 \%$ of staphylococcal

TABLE 1 | Primer sequences and PCR fragment size of tested MLS resistance genes.

\begin{tabular}{|c|c|c|c|}
\hline Gene & Primers sequence $\left(5^{\prime}-3^{\prime}\right)$ & $\begin{array}{c}\text { PCR } \\
\text { fragment } \\
\text { size (bp) }\end{array}$ & Reference \\
\hline ermA & $\begin{array}{l}\text { F: TCTAAAAAGCATGTAAAAGAA } \\
\text { R: CTTCGATAGTTATTAATATTAG }\end{array}$ & 645 & (10) \\
\hline ermB & $\begin{array}{l}\text { F: GAAAAGTACTCAACCAAATA } \\
\text { R: AGTAACGGTACTTAAATTGTTTA }\end{array}$ & 639 & (10) \\
\hline ermC & $\begin{array}{l}\text { F: TCAAAACATAATATAGATAAA } \\
\text { R: GCTAATATTGTITAAATCGTCAAT }\end{array}$ & 642 & $(10)$ \\
\hline msrA & $\begin{array}{l}\text { F: GGCACAATAAGAGTGTITAAAGG } \\
\text { R: AAGTTATATCATGAATAGATTGTCCTGTT }\end{array}$ & 940 & (11) \\
\hline$m s r \mathrm{~B}$ & $\begin{array}{l}\text { F: TATGATATCCATAATAATTATCCAATC } \\
\text { R: AAGTTATATCATGAATAGATTGTCCTGTT }\end{array}$ & 595 & (11) \\
\hline InuA & $\begin{array}{l}\text { F: GGTGGCTGGGGGGTAGATGTATTAACTGG } \\
\text { R: GCTTCTITGAAATACATGGTATIITCGATC }\end{array}$ & 323 & $(12)$ \\
\hline $\ln u B$ & $\begin{array}{l}\text { F: CCTACCTATTGTITGTGGAA } \\
\text { R: ATAACGTTACTCTCCTATTC }\end{array}$ & 925 & $(12)$ \\
\hline IsaA & $\begin{array}{l}\text { F: GGCAATCGCTTGTGTITAGCG } \\
\text { R: GTGAATCCCATGATGTTGATACC }\end{array}$ & 1,200 & (13) \\
\hline
\end{tabular}

MLS, macrolides, lincosamides, and streptogramins; PCR, polymerase chain reaction. 
isolates showing iMLSb, M/MSb, or LSa/b resistance phenotype, MLS resistance genes have not been found.

The observed MLS phenotypes of resistance were the most frequently determined by a single gene, and those genes mostly were $m s r \mathrm{~A} / \mathrm{B}$ and erm $\mathrm{C}$. However, these phenotypes were also

TABLE 2 | Distribution of MLS resistance phenotypes by origin of the staphylococcal isolate (community-acquired versus hospital-acquired); $p$-value $<0.05$ is considered as statistically significant.

\begin{tabular}{lccc}
\hline & \multicolumn{3}{c}{ Staphylococcus spp., $\boldsymbol{n}(\%)$} \\
\cline { 2 - 4 } & Community-acquired & Hospital-acquired & $\boldsymbol{p}$-Value \\
\hline Er/Cli S & $546(39.9)$ & $97(35.1)$ & 0.16 \\
cMLSb & $128(9.3)$ & $19(6.8)$ & 0.20 \\
M/MSb & $218(15.9)$ & $71(25.7)$ & 0.0001 \\
iMLSb & $461(33.7)$ & $87(31.5)$ & 0.52 \\
LSa/b & $14(1.0)$ & $2(0.7)$ & 1.0 \\
Total & $1,367(100.0)$ & $276(100.0)$ & \\
\hline
\end{tabular}

Er/Cli S, susceptibility to erythromycin and clindamycin; CMLSb, constitutive resistance to macrolide-lincosamide-streptogramin B: M/MSb, resistance to macrolide/ macrolide-streptogramin B; iMLSb, inducible resistance to macrolide-lincosamidestreptogramin $B ; L S a / b$, resistance to lincosamide-streptogramin A/streptogramin B. determined by combinations of two or more resistance genes and the most common detected gene combinations were erm $\mathrm{C}+m s r \mathrm{~A} / \mathrm{B}, e r m \mathrm{~B}+l s a \mathrm{~A}$, and $e r m \mathrm{~B}+m s r \mathrm{~A} / \mathrm{B}$.

erm $\mathrm{A}$ and erm $\mathrm{C}$ genes were the most common in methicillinsensitive $S$. aureus (MSSA) isolates, while ermB gene was the most frequent among methicillin-resistant coagulase-negative staphylococci (MRCNS). The greatest presence of $\ln u \mathrm{~A}$ genes was detected in methicillin-sensitive coagulase-negative staphylococci (MSCNS), whereas lsaA gene was, as a single case, detected only in S. aureus isolates. The highest percentage of msrA/B gene was identified in MSCNS. The combinations of two or more resistance genes were the most common in methicillin-resistant staphylococci isolates (Table S1 in Supplementary Material).

$\mathrm{M} / \mathrm{MSb}$ resistance phenotype was mostly determined by $m s r \mathrm{~A} / \mathrm{B}(95.6 \%)$ (Figure 1A), while LSa/b phenotype was mostly determined by lnuA gene (56.3\%) (Figure 1B). ermC (29.4\%) and ermA (25.5\%) were the most prevalent genes determined as a single gene iMLSb phenotype (Figure 1C). However, ermC (28.9\%) was the most common gene in staphylococcal isolates with cMLSbresistant phenotype. This phenotype was also characterized by the presence of great number of combinations with two or more resistance genes. The most common gene combinations in these
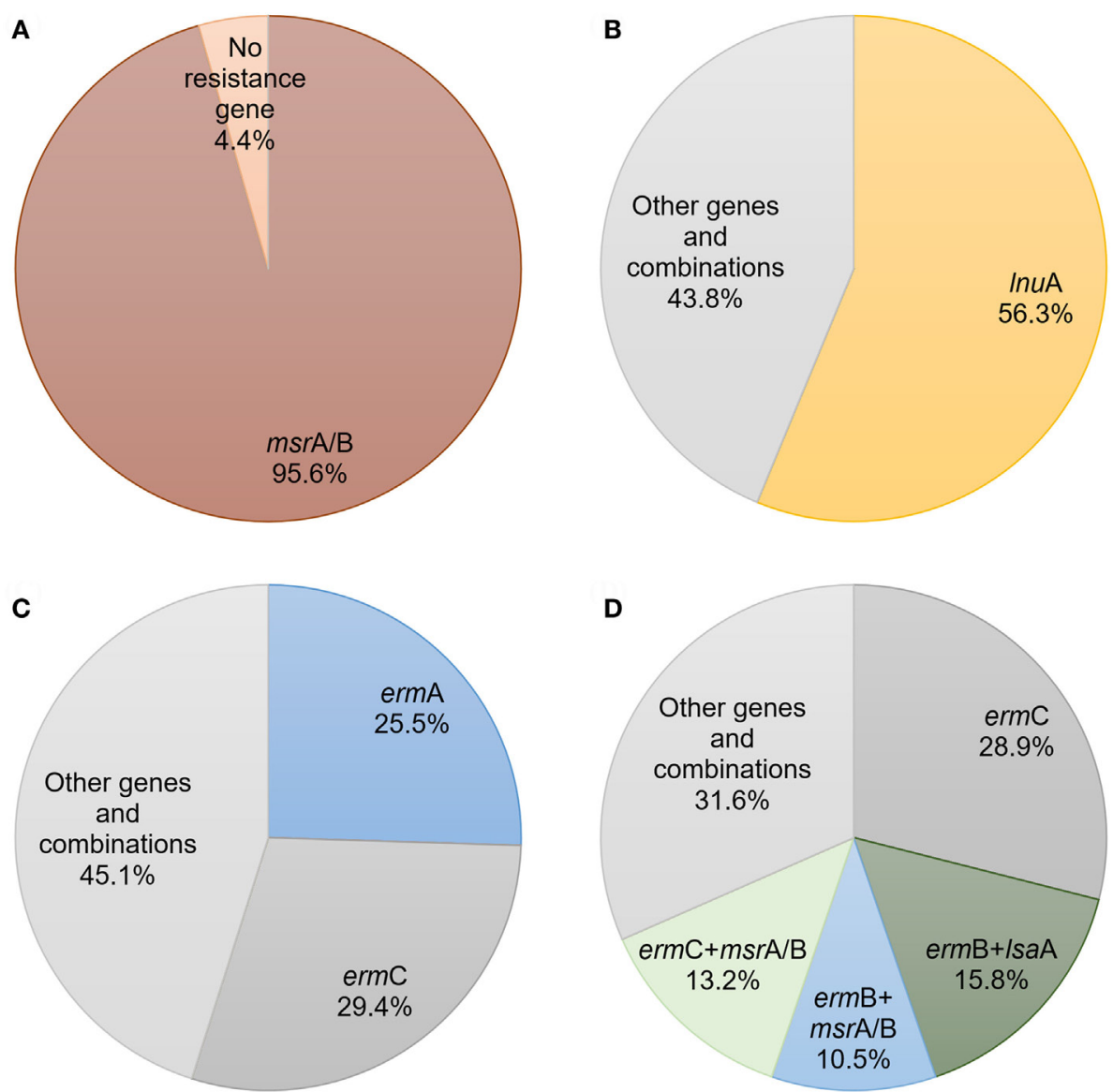

FIGURE 1 | The prevalence and expression of macrolides, lincosamides, and streptogramins resistance genes and their combinations among different phenotypes of staphylococcal isolates: (A) resistance to macrolide/macrolide-streptogramin B; (B) resistance to lincosamide-streptogramin A/streptogramin B; (C) inducible resistance to macrolide-lincosamide-streptogramin B; (D) constitutive resistance to macrolide-lincosamide-streptogramin B. 
isolates were erm $\mathrm{B}+l s a \mathrm{~A}(15.8 \%)$, erm $\mathrm{C}+m s r \mathrm{~A} / \mathrm{B}(13.2 \%)$, and erm $\mathrm{B}+\mathrm{msr} \mathrm{A} / \mathrm{B}(10.5 \%)$ (Figure 1D) (Table S2 in Supplementary Material). This trend was especially observed in methicillinresistant S. aureus (MRSA) (58.3\%) and MRCNS (90.9\%) strains. Combinations of genes predominantly determined cMLSb phenotype in methicillin-resistant staphylococci. In accordance with this observation, in one MRCNS strain the combination of four genes $(e r m \mathrm{~B}+\ln u \mathrm{~A}+\ln u \mathrm{~B}+\operatorname{ls} a \mathrm{~A})$ has been detected.

Distribution of MLS resistance genes and their combinations by origin of the staphylococcal isolate are shown in Table 3. The $m s r \mathrm{~A} / \mathrm{B}$ gene was statistically significantly more common in hospital-acquired staphylococci isolates than in communityacquired staphylococci strains $(p<0.05)$. There are no statistically significant differences between percentage of staphylococci harboring the rest of MLS resistance genes acquired in community and hospital settings $(p>0.05)$.

\section{DISCUSSION}

Soon after penicillin was introduced, $S$. aureus strains resistant to penicillin had been found. These penicillin-resistant $S$. aureus strains first became prevalent in health-care settings but then, these strains have also been spread into the community. Rapidly after introduction of newer antibiotics such as methicillin, erythromycin, and clindamycin, S. aureus and some other staphylococci species have become resistant to those and other antibiotics. Finally, multidrug-resistant Staphylococcus strains have evolved, often causing infections with a fatal outcome (15). Multidrug-resistant $S$. aureus and CNS have become a common cause of both hospital- and community-acquired infection. The necessity in phenotypic and genotypic tests for discovering

TABLE 3 | Distribution of macrolides, lincosamides, and streptogramins resistance genes by origin of the staphylococcal isolate (community-acquired versus hospital-acquired); $p$-value $<0.05$ is considered as statistically significant.

\begin{tabular}{|c|c|c|c|}
\hline & \multicolumn{3}{|c|}{ Staphylococcus spp., $\boldsymbol{n}(\%)$} \\
\hline & $\begin{array}{l}\text { Community- } \\
\text { acquired }\end{array}$ & $\begin{array}{l}\text { Hospital- } \\
\text { acquired }\end{array}$ & $p$-Value \\
\hline ermA & $13(8.6)$ & $1(3.4)$ & 0.47 \\
\hline ermB & $4(2.6)$ & $2(6.9)$ & 0.25 \\
\hline ermC & $24(16.0)$ & $2(6.9)$ & 0.26 \\
\hline InuA & 7 (4.6) & $3(10.3)$ & 0.21 \\
\hline IsaA & 2 (1.3) & 0 & 1.00 \\
\hline$m s r A / B$ & $34(22.6)$ & $13(44.8)$ & 0.02 \\
\hline ermA + ermC & $1(0.6)$ & 0 & 1.00 \\
\hline ermA + msrA/B & $2(1.3)$ & 0 & 1.0 \\
\hline ermB + ermC & $1(0.6)$ & 0 & 1.0 \\
\hline ermB + IsaA & $5(3.3)$ & $1(3.4)$ & 1.0 \\
\hline$e r m \mathrm{~B}+m s r \mathrm{~A} / \mathrm{B}$ & $4(2.6)$ & 0 & 1.0 \\
\hline erm $\mathrm{C}+$ IsaA & $1(0.6)$ & 0 & 1.0 \\
\hline$e r m \mathrm{C}+m s r A / B$ & $7(4.6)$ & $1(3.4)$ & 1.0 \\
\hline $\ln u A+\ln u B$ & $1(0.6)$ & 0 & 1.0 \\
\hline$m s r A / B+$ lsaA & $1(0.6)$ & 0 & 1.0 \\
\hline ermB + msrA/B + IsaA & 0 & $1(3.4)$ & 0.16 \\
\hline$e r m \mathrm{C}+m s r \mathrm{~A} / \mathrm{B}+\ln u \mathrm{~A}$ & $1(0.6)$ & 0 & 1.0 \\
\hline$e r m \mathrm{~B}+\ln u \mathrm{~A}+\ln u \mathrm{~B}+\operatorname{ls} a \mathrm{~A}$ & $1(0.6)$ & 0 & 1.0 \\
\hline No resistance gene & 41 (27.3) & 5 (17.2) & 0.35 \\
\hline Total & $150(100)$ & $29(100)$ & \\
\hline
\end{tabular}

resistance in clinically relevant staphylococci has become clearer with the occurrence of strains having borderline minimum inhibitory concentrations of antibiotics. Identifying MLS resistance phenotype is very important, because iMLSb phenotype under intensive antibiotic selective pressure converts into cMLSb phenotype and may lead to treatment failure in patients with serious staphylococcal infection (16).

In our study, the greatest number of staphylococcal isolates showed sensitivity to both macrolide and lincosamide and the most frequent phenotype of resistance was iMLSb, while cMLSb phenotype was almost the rarest MLS resistance phenotype. This pattern of MLS resistance was the same among community- and hospital-associated staphylococcal isolates. Different distribution of MLS resistance phenotype among methicillin-resistant staphylococci isolates in India has been reported by Zachariah et al. (16). They found that the most prevalent phenotype was $\mathrm{M} / \mathrm{MSb}$, and the second most prevalent phenotype was iMLSb. In contrast, Hamilton-Miller and Shah, Fokas et al. have found that iMLSb phenotype was more prevalent in relation to the other phenotypes $(17,18)$, data similar to our study. The distribution of MLS resistance phenotypes may vary depending on geographic area and even the type of patient. This difference occurs because of various prescription and consumption rates of macrolides and lincosamides in different geographical regions and even institutions in the same region because of different origins of the isolates (hospital- versus community-acquired) (19). In our study, we found that M/MSb phenotype was significantly higher in inpatient than outpatient isolates $(p<0.05)$. Similarly, we have detected that msrA gene determining M/ MSb phenotype more frequently in hospital-acquired than in community-acquired staphylococcal isolates $(p<0.05)$. This finding suggests importance of phenotypic differentiation of truly clindamycin sensitive from false clindamycin-sensitive staphylococci (iMLSb), especially for staphylococci isolates from hospital environments. In contrast, Lall and Sahni suggested a higher prevalence of iMLSb in health care-associated Staphylococcus than community associated (86.5 versus $13.4 \%$, respectively) (20). Yet, the implication of their study is the same as ours.

The molecular analysis identified the msrA gene, encoding active efflux pumps in staphylococci bacterial cells, as the most frequent MLS resistance gene. More than half of the macrolide-resistant isolates of staphylococci harbored the msrA gene either alone or in combination with erm genes. Recent studies demonstrated similar results $(21,22)$. The erm $\mathrm{C}$ gene was the most common among all erm genes in both $S$. aureus and CNS exhibiting cMLSb or iMLSb phenotype. Similar data were reported by Juda et al. (23). In Brazil, Coutinho et al. (24) reported low frequency of the ermB gene, data which did not differ from our study. However, there was only a small number of staphylococcal isolates with the unusual LSa/b phenotype harboring $\ln u \mathrm{~A}$ and $l s a \mathrm{~A}$ genes, in this study. These results are in line with the studies of Singh and Murray and Deng et al. $(13,25)$. The most common detected gene combinations in our study were $e r m \mathrm{C}+m s r \mathrm{~A} / \mathrm{B}, e r m \mathrm{~B}+l s a \mathrm{~A}$, and $\operatorname{erm} \mathrm{B}+m s r \mathrm{~A} / \mathrm{B}$. As expected, we identified the greatest number of resistance gene combinations in methicillin-resistant staphylococci isolates. Likewise, 
the simultaneous presence of two or more MLS resistance genes in the same staphylococcal isolate has been reported previously for hospital-acquired MRSA and MRCNS isolates in Argentina, USA, and Poland, respectively (26-28). We proposed that the majority of isolates with simultaneous presence of two or more MLS resistance genes would have been found among strains isolated from inpatients. Regardless of our expectation, there were no significant differences in number of staphylococcal isolates with MLS gene combinations between hospital- and communityacquired strains $(p>0.05)$. 9.8\% of our isolates showing iMLSb, $\mathrm{M} / \mathrm{MSb}$, or LSa/b resistance phenotype had no MLS resistance gene. Similar finding has been reported in other studies $(19,29)$.

In the present study, the highest percentage of $m s r \mathrm{~A} / \mathrm{B}$ gene was identified in MSCNS. Macrolide resistance due to $\mathrm{msrA}$ was more prevalent in CNS than in S. aureus. Similar data were observed in one study (30), whereas in other studies, the presence of $m s r A / B$ genes has been reported in different rates (31-33). In our study, ermA and erm $\mathrm{C}$ genes were most common in MSSA isolates. In contrast, Westh et al. (34) detected that ermA gene is most common in MRSA isolates, whereas erm $\mathrm{C}$ gene was mostly found among their MRCNS isolates. We found erm B gene mostly among MRCNS, whereas in the study conducted by Bouchami et al. erm B has not been detected in staphylococci (35). In our study, $\ln u \mathrm{~A}$ gene was the most commonly detected in MSCNS and similar, almost the same, results were found in study by Lina et al. (36). For the first time, we detected $l s a A$ gene as a single gene in $S$. aureus isolates. $l s a \mathrm{~A}$ gene in enterococci encodes a protein, similar to ABC transporters, which export antimicrobials belonging to the MLS family (37). The $l s a \mathrm{~A}$ gene as an intrinsic gene of Enterococcus faecalis showed a high degree of similarity to a novel gene encoding the $\mathrm{ABC}$ transporter (lsaE gene), which has been already detected in staphylococci. Transfer of resistance from enterococci to $S$. aureus has also been reported to occur for the tetracycline resistance gene tet $\mathrm{L}$ and the trimethoprim resistance gene $d f r \mathrm{~K}$ (38). Yet, the lsaA gene, originating from Enterococcus spp. (39), has never been reported before for $S$. aureus.

In our study, $\mathrm{M} / \mathrm{MSb}$ resistance phenotype in staphylococci isolates was mostly determined by $m s r \mathrm{~A} / \mathrm{B}$, while $\mathrm{LSa} / \mathrm{b}$ phenotype was mostly determined by $\ln u \mathrm{~A}$ gene. erm $\mathrm{C}$ and erm $\mathrm{A}$ were the most prevalent single genes determining iMLSb phenotype. In other studies, the presence of erm $\mathrm{C}$ and $\mathrm{erm} \mathrm{A}$ genes has been reported with different rates $(19,29,33,40,41)$. However, erm C gene was the most common gene in staphylococcal isolates with cMLSb-resistant phenotype. This result is in accordance to the previous report (42). cMLSb phenotype was also characterized by the presence of great number of gene combinations: erm $\mathrm{B}+l s a \mathrm{~A}$, erm $\mathrm{C}+m s r \mathrm{~A} / \mathrm{B}$, and erm $\mathrm{B}+m s r \mathrm{~A} / \mathrm{B}$. This trend was particularly observed in MRSA and MRCNS strains, where these combinations of genes predominantly determined cMLSb phenotype. In accordance with this observation, in one MRCNS strain the combination of four genes $(e r m \mathrm{~B}+\ln u \mathrm{~A}+\ln u \mathrm{~B}+\operatorname{ls} a \mathrm{~A})$ has been detected. Hosseini et al. have come across pattern of similar kind (43).

After all, according to all investigated staphylococci, the iMLSb was the most frequently occurring phenotype. The most frequently isolated MLS resistance genes among staphylococci were $m s r \mathrm{~A} / \mathrm{B}$ and $e r m \mathrm{C} . \mathrm{M} / \mathrm{MSb}(m s r \mathrm{~A} / \mathrm{B}), \mathrm{LSa} / \mathrm{b}(\operatorname{lnu} \mathrm{A})$, and
iMLSb (ermA/C) were dominantly determined with a single gene. cMLSb phenotype was mostly determined by erm $\mathrm{C}$ and combinations of genes $(\mathrm{erm} \mathrm{C}+m s r \mathrm{~A} / \mathrm{B}$ and $m s r \mathrm{~A} / \mathrm{B}+l s a \mathrm{~A})$. The $\mathrm{M} / \mathrm{MSb}$ phenotype and $m s r \mathrm{~A} / \mathrm{B}$ gene that determine this phenotype were significantly more frequent in staphylococci acquired in hospital than in community. Based on these results, clindamycin can be used for empiric antimicrobial therapy for infections such as skin and soft tissue infections in inpatients, before the individual's laboratory results of in vitro antibiotic susceptibility testing are available.

However, the iMLSb phenotype was the most common in our study, either among community- or hospital-acquired Staphylococcus isolates. Therefore, the big concern remains for patients with severe staphylococcal infection treated with clindamycin, they could be at risk of unsuccessful treatment and poor outcome if staphylococcal isolates showed inducible clindamycin resistance (44). The simple test like D-test on staphylococcal strains can separate the isolates with genetic mechanism for the development of clindamycin resistance during therapy from those that are truly susceptible to clindamycin. If we do not perform routinely D-test, all strains of staphylococci including those with iMLSb resistance phenotype will be reported as clindamycin sensitive. On the contrary, if all erythromycin-resistant staphylococcal strains are declared as a resistant to clindamycin, a safe and effective antibiotic will be omitted from the treatment in patients infected with isolates carrying an active efflux mechanism that confers only resistance to macrolides (35). In our study, we reported that $56.7 \%$ actually (M/MSb and susceptibility to erythromycin and clindamycin) and 33.4\% falsely (iMLSb) clindamycin-sensitive Staphylococcus spp. strains have led to such a small percentage of clindamycin resistance 9.9\% (cMLSb and $\mathrm{LSa} / \mathrm{b}$ ) instead of $49.0 \%$ (iMLSb and cMLSb and LSa/b) among staphylococcal isolates. Therefore, it is necessary to monitor the prevalence of iMLS phenotype, especially in areas where the occurrence of methicillin-resistant staphylococcal strains resulted in empirical use of macrolides and lincosamides for the treatment of staphylococcal infections. The prevalence of iMLSb phenotypes may change over time, so it is necessary to perform sporadically survey of MLS resistance phenotypes, particularly where the D-test is not performed routinely.

\section{AUTHOR CONTRIBUTIONS}

MM contributed to the conception, design, and drafting of the study, data acquisition and processing, and writing of the manuscript. JČ contributed to the conception of the study, data acquisition, and corrected the manuscript. DV contributed to the design of the study, data analysis and interpretation, and corrected the manuscript. MŠ contributed to the conception of the study, data analysis and interpretation, and corrected the manuscript. SM contributed to the conception of the study, data analysis and interpretation, and drafting of the study. MV contributed to the conception and design of the study, data analysis and interpretation, and corrected the manuscript. DB contributed to the conception and design of the study, guided in data acquisition, analysis, and interpretation, and corrected the manuscript. 


\section{FUNDING}

This study was supported by the Ministry of Science and Technology of the Republic of Serbia under Grant Number III41010.

\section{REFERENCES}

1. Becker K, Heilmann C, Peters G. Coagulase-negative staphylococci. Clin Microbiol Rev (2014) 27:870-926. doi:10.1128/CMR.00109-13

2. Leclercq R, Courvalin P. Bacterial resistance to macrolide, lincosamide, and streptogramin antibiotics by target modification. Antimicrob Agents Chemother (1991) 35:1267-72. doi:10.1128/AAC.35.7.1273

3. Roberts MC, Sutcliffe J, Courvalin P, Jensen LB, Rood J, Seppala H. Nomenclature for macrolide and macrolide-lincosamide-streptogramin B resistance determinants. Antimicrob Agents Chemother (1999) 43:2823-30.

4. Li L, Feng W, Zhang Z, Xue H, Zhao X. Macrolide-lincosamide-streptogramin resistance phenotypes and genotypes of coagulase-positive Staphylococcus aureus and coagulase-negative staphylococcal isolates from bovine mastitis. BMC Vet Res (2015) 11:168. doi:10.1186/s12917-015-0492-8

5. Schwendener S, Vincent Perreten V. New MLSB resistance gene erm(43) in Staphylococcus lentus. Antimicrob Agents Chemother (2012) 56:4746-52. doi:10.1128/AAC.00627-12

6. Duran N, Ozer B, Duran GG, Onlen Y, Demir C. Antibiotic resistance genes \& susceptibility patterns in staphylococci. Indian JMed Res (2012) 135: 389-96.

7. Hollenbeck BL, Rice LB. Intrinsic and acquired resistance mechanisms in Enterococcus. Virulence (2012) 3:421-33. doi:10.4161/viru.21282

8. Sundlov JA, Gulick AM. Insights into resistance against lincosamide antibiotics. Structure (2009) 17:1549-50. doi:10.1016/j.str.2009.11.001

9. CLSI. Performance Standards for Antimicrobial Susceptibility Testing. 21th Informational Supplement M100-S21. Wayne, PA: Clinical and Laboratory Standards Institute (2011).

10. Rizzotti L, Simeoni D, Cocconcelli P, Gazzola S, Dellaglio F, Torriani S. Contribution of enterococci to the spread of antibiotic resistance in the production chain of swine meat commodities. J Food Prot (2005) 68:955-65. doi:10.4315/0362-028X-68.5.955

11. Matsuoka M, Jánosi L, Endou K, Nakajima Y. Cloning and sequences of inducible and constitutive macrolide resistance genes in Staphylococcus aureus that correspond to an ABC transporter. FEMS Microbiol Lett (1999) 181:91-100. doi:10.1111/j.1574-6968.1999.tb08830.x

12. Lozano C, Aspiroz C, Sáenz Y, Ruiz-García M, Royo-García G, Gómez-Sanz E, et al. Genetic environment and location of the $\operatorname{lnu}(\mathrm{A})$ and $\operatorname{lnu}(\mathrm{B})$ genes in methicillin-resistant Staphylococcus aureus and other staphylococci of animal and human origin. J Antimicrob Chemother (2012) 67:2804-8. doi:10.1093/jac/dks320

13. Singh KV, Murray BE. Differences in the Enterococcus faecalis lsa locus that influence susceptibility to quinupristin-dalfopristin and clindamycin. Antimicrob Agents Chemother (2005) 49:32-9. doi:10.1128/AAC. 49.1.32-39.2005

14. Wen D, Zhang C. Universal multiplex PCR: a novel method of simultaneous amplification of multiple DNA fragments. Plant Methods (2012) 8:32. doi:10.1186/1746-4811-8-32

15. Healy CM, Hulten KG, Palazzi DL, Campbell JR, Baker CJ. Emergence of new strains of methicillin-resistant Staphylococcus aureus in a neonatal intensive care unit. Clin Infect Dis (2004) 39:1460-6. doi:10.1086/425321

16. Zachariah R, Basireddy S, Kabra V, Singh M, Ali S, Sardar A. Phenotypic characterization of macrolide and lincosamide resistance patterns in clinical isolates of staphylococci. J Dr NTR Univ Health Sci (2016) 5:187-91. doi:10.4103/2277-8632.191847

17. Hamilton-Miller JMT, Shah S. Patterns of phenotypic resistance to the macrolide-lincosamide-ketolide-streptogramin group of antibiotics in staphylococci. J Antimicrob Chemother (2000) 46:941-9. doi:10.1093/jac/ 46.6.941

18. Fokas S, Fokas S, Tsironi M, Kalkani M, Dionysopouloy M. Prevalence of inducible clindamycin resistance in macrolide-resistant Staphylococcus spp. Clin Microbiol Infect (2005) 11:337-40. doi:10.1111/j.1469-0691.2005.01101.x

\section{SUPPLEMENTARY MATERIAL}

The Supplementary Material for this article can be found online at http://journal.frontiersin.org/article/10.3389/fpubh.2017.00200/ full\#supplementary-material.

19. Aktas Z, Aridogan A, Kayacan CB, Aydin D. Resistance to macrolide, lincosamide and streptogramin antibiotics in Staphylococcus isolated in Istanbul, Turkey. J Microbiol (2007) 45:286-90.

20. Lall M, Sahni AK. Prevalence of inducible clindamycin resistance in Staphylococcus aureus isolated from clinical samples. Med J Armed Forces India (2014) 70:43-7. doi:10.1016/j.mjafi.2013.01.004

21. Lenart-Boroń A, Wolny-Koładka K, Stec J, Kasprowic A. Phenotypic and molecular antibiotic resistance determination of airborne coagulase negative Staphylococcus spp. strains from healthcare facilities in Southern Poland. Microb Drug Resist (2016) 22:515-22. doi:10.1089/mdr.2015.0271

22. Goudarzi G, Farzad Tahmasbi F, Anbari K, Ghafarzadeh M. Distribution of genes encoding resistance to macrolides among staphylococci isolated from the nasal cavity of hospital Employees in Khorramabad, Iran. Iran Red Crescent Med J (2016) 18:e25701. doi:10.5812/ircmj.25701

23. Juda M, Chudzik-Rzad B, Malm A. The prevalence of genotypes that determine resistance to macrolides, lincosamides, and streptogramins B compared with spiramycin susceptibility among erythromycin-resistant Staphylococcus epidermidis. Mem Inst Oswaldo Cruz (2016) 111:155-60. doi:10.1590/0074-02760150356

24. Coutinho VL, Paiva RM, Reiter KC, de-Paris F, Barth AL, Machado AB. Distribution of erm genes and low prevalence of inducible resistance to clindamycin among staphylococci isolates. Braz J Infect Dis (2010) 14:564-8. doi:10.1016/S1413-8670(10)70113-6

25. Deng F, Wang H, Liao Y, Li J, Feßler AT, Geovana BM, et al. Detection and genetic environment of pleuromutilin-lincosamide-streptogramin a resistance genes in staphylococci isolated from pets. Front Microbiol (2017) 8:234. doi:10.3389/fmicb.2017.00234

26. Faccone D, Togneri AM, Podesta L, Perez M, Gagetti P, Sanchez S, et al. MRSA pediatric clone expressing ermC plus lnuA genes causing nosocomial transmission and healthcare workers colonization in a neonatal intensive care unit. Infect Genet Evol (2014) 25:78-80. doi:10.1016/j. meegid.2014.04.005

27. Szczuka E, Makowska N, Bosacka K, Słotwińska A, Kaznowski A. Molecular basis of resistance to macrolides, lincosamides and streptogramins in Staphylococcus hominis strains isolated from clinical specimens. Folia Microbiol (Praha) (2016) 61:143-7. doi:10.1007/s12223-015-0419-6

28. Steward CD, Raney PM, Morrell AK, Williams PP, McDougal LK, Jevitt L, et al. Testing for induction of clindamycin resistance in erythromycin-resistant isolates of Staphylococcus aureus. JClin Microbiol (2005) 43:1716-21. doi:10.1128/JCM.43.4.1716-1721.2005

29. Moosavian M, Shoja S, Rostami S, Torabipour M, Farshadzadeh Z. Inducible clindamycin resistance in clinical isolates of Staphylococcus aureus due to erm genes, Iran. Iran J Microbiol (2014) 6:421-7.

30. Zmantar T, Kouidhi B, Miladi H, Bakhrouf A. Detection of macrolide and disinfectant resistance genes in clinical Staphylococcus aureus and coagulase-negative staphylococci. BMC Res Notes (2011) 4:453. doi:10.1186/ 1756-0500-4-453

31. Fiebelkorn KR, Crawford SA, McElmeel ML, Jorgensen JH. Practical disk diffusion method for detection of inducible clindamycin resistance in Staphylococcus aureus and coagulase-negative staphylococci. J Clin Microbiol (2003) 41:4740-4. doi:10.1128/JCM.41.10.4740-4744.2003

32. Novotna G, Adamkova V, Janata J, Melter O, Spizek J. Prevalence of resistance mechanisms against macrolides and lincosamides in methicillin-resistant coagulase-negative staphylococci in the Czech Republic and occurrence of an undefined mechanism of resistance to lincosamides. Antimicrob Agents Chemother (2005) 49:3586-9. doi:10.1128/AAC.49.8.3586-3589.2005

33. Cetin ES, Gunes H, Kaya S, Aridogan BC, Demirci M. Distribution of genes encoding resistance to macrolides, lincosamides and streptogramins among clinical staphylococcal isolates in a Turkish university hospital. JMicrobiol Immunol Infect (2010) 43:524-9. doi:10.1016/S1684-1182 (10)60081-3 
34. Westh H, Hougaard DM, Vuust J, Rosdahl VT. erm genes in erythromycinresistant Staphylococcus aureus and coagulase-negative staphylococci. APMIS (1995) 103:225-32. doi:10.1111/j.1699-0463.1995.tb01099.x

35. Bouchami O, Achour W, Hassen AB. Prevalence and mechanisms of macrolide resistance among Staphylococcus epidermidis isolates from neutropenic patients in Tunisia. Clin Microbiol Infect (2007) 13:103-6. doi:10.1111/j.1469-0691.2006.01567.x

36. Lina G, Quaglia A, Reverdy ME, Leclercq R, Vandenesch F, Etienne J. Distribution of genes encoding resistance to macrolides, lincosamides, and streptogramins among staphylococci. Antimicrob Agents Chemother (1999) 43:1062-6.

37. Dina J, Malbruny B, Leclercq R. Nonsense mutations in the lsa-like gene in Enterococcus faecalis isolates susceptible to lincosamides and streptogramins A. Antimicrob Agents Chemother (2003) 47:2307-9. doi:10.1128/ AAC.47.7.2307-2309.2003

38. Lopez M, Kadlec K, Schwarz S, Torres C. First detection of the staphylococcal trimethoprim resistance gene dfrK and the dfrK-carrying transposon Tn559 in enterococci. Microb Drug Resist (2012) 18:13-8. doi:10.1089/mdr. 2011.0073

39. Wendlandt S, Lozano C, Kadlec K, Gomez-Sanz E, Zarazaga M, Torres C, et al. The enterococcal $\mathrm{ABC}$ transporter gene lsa(E) confers combined resistance to lincosamides, pleuromutilins and streptogramin A antibiotics in methicillin-susceptible and methicillin-resistant Staphylococcus aureus. J Antimicrob Chemother (2013) 68:473-5. doi:10.1093/jac/dks398

40. Ghanbari F, Ghajavand H, Havaei R, Jami MS, Khademi F, Heydari L, et al. Distribution of erm genes among Staphylococcus aureus isolates with inducible resistance to clindamycin in Isfahan, Iran. Adv Biomed Res (2016) 5:62. doi:10.4103/2277-9175.179184
41. Saderi H, Emadi B, Owlia P. Phenotypic and genotypic study of macrolide, lincosamide and streptogramin B (MLSB) resistance in clinical isolates of Staphylococcus aureus in Tehran, Iran. Med Sci Monit (2011) 17:48-53. doi:10.12659/MSM.881386

42. Pereira JN, Rabelo MA, Lima JL, Neto AM, Lopes AC, Maciel MA. Phenotypic and molecular characterization of resistance to macrolides, lincosamides and type B streptogramin of clinical isolates of Staphylococcus spp. of a university hospital in Recife, Pernambuco, Brazil. Braz J Infect Dis (2016) 20:276-81. doi:10.1016/j.bjid.2016.03.003

43. Hosseini SS, Niakan M, Saderi H, Motallebi M, Taherikalani M, Asadollahi K, et al. Frequency of genes encoding erythromycin ribosomal methylases among Staphylococcus aureus clinical isolates with different D-phenotypes in Tehran, Iran. Iran J Microbiol (2016) 8:161-7.

44. Prabhu K, Rao S, Rao V. Inducible clindamycin resistance in Staphylococcus aureus isolated from clinical samples. JLab Physicians (2011) 3:25-7. doi:10.4103/0974-2727.78558

Conflict of Interest Statement: The authors declare that the research was conducted in the absence of any commercial or financial relationships that could be construed as a potential conflict of interest.

Copyright $\odot 2017$ Mišić, Čukić, Vidanović, Šekler, Matić, Vukašinović and Baskić. This is an open-access article distributed under the terms of the Creative Commons Attribution License (CC BY). The use, distribution or reproduction in other forums is permitted, provided the original author(s) or licensor are credited and that the original publication in this journal is cited, in accordance with accepted academic practice. No use, distribution or reproduction is permitted which does not comply with these terms. 